\title{
Numerical assessment for fire safety in school buildings
}

\author{
M.F. Mohd Idris \\ School of Housing Building and Planning \\ Universiti Sains Malaysia, 11800 Minden, Penang.
}

\begin{abstract}
There is a need for professionals to advice regarding fire safety requirements for buildings in order to solve the problems of fire safety and fire risk. Decisions made by individuals are normally bias and not accepted globally. This paper introduces the steps taken by the researcher in dealing with Fire Safety focusing particularly on the usage of Delphi technique in making decision by a group of professionals. This technique introduces a numerical approach (point scheme) in assessing policy and objectives set by an organization. The danger caused by fire is one of the risks within the Educational Establishment under the supervision of the Ministry of Education is taken as the case study. In dealing with fire safety policy at school, an approach was taken to propose the Delphi Technique in assessing the achievability of the fire safety objectives. It is difficult for a single person to make a decision that deals with thousands of educational buildings with different forms and functions. This paper shows that the Delphi technique can be adopted by other organization to achieve their goals or objectives or policy set. Another important aspect is also to encourage other personnel within the establishment to be exposed to the knowledge of fire safety by indirect training, knowing the life cycle of buildings in views of fire safety. This will enhance the achievement of a fire free environment for occupants together with the continuity of mission.
\end{abstract}

\section{Introduction}

One of the most important issues today is fire. Fire has been recognised for a long time as a major part of the threat within the building design and 


\section{Environmental Health Risk}

construction processes as it affects the whole of the community and their activities within buildings. Fire impact could be in the form of direct or indirect losses, fire fatalities or fire injuries of human lives, properties, and may have major impact on the social, environment and economic development. It has been accepted that fire disasters do have a huge impact on the whole society. A serious study on how to reduce the losses from fire will continue to be carried out by researchers, insurance companies, Buildings Standards organisations and other parties with an interest in the impact of fire. In order to make decisions on fire safety easier and more promising based on the engineering design point of view, predictive tools need to be introduced. These tools will probably involve expert opinions and fire models that can be used to assess the fire hazard associated with the level of severity expected to be within an area with a specified scenario. The fire risk assessment results will assist in the implementation of the fire safety system in those particular areas based upon the similar scenario. Basically, the process of decision making for a fire safety system to be installed for a particular area may be considered in the following steps:

Step 1: Choose the Area

Step 2: Define the Type of Occupancy and Activity(s)

Step 3: Assess The Fire Hazard

Step 4: Assess The Fire Risk

Step 5: The Availability of the Fire Safety System(s)

Step 6: The System Cost and Economics (Value for money)

Step 7: Performance and Maintainability

\section{Purpose of study}

The purpose of having the fire safety assessment checklist for school buildings and occupants is to provide guidelines for the evaluator or any other building authorities and surveyors to carry out the task to ensure the establishment is safe from danger of fire at an acceptable level. The checklists consist of numbers that apply to the fire safety components and other fire safety hierarchies, which contribute towards attaining the Fire Safety Policy of the Educational Establishment. The numbers have been generated by a group of fire safety professionals. Once the number has been established, it is available for the evaluator to use it as an assistant in making the assessment or evaluation process and to make decisions for the level of fire safety within a school. The checklist existence is important in order to introduce the point's scheme appraisal throughout the fire safety assessment within the educational establishment. The application of the check lists are used to establish the procedure that every fire safety evaluator needs to follow in order to achieve the standard of fire safety via the set objectives and tactics. By having the number, the whole fire safety assessment process can be done with ease by the selected evaluators on each of the safety system and also the synthesis of the fire performance of the school buildings. 


\section{Delphi Group \& the evaluation scheme}

A lot of new fire safety technology introduced into the market and it is important that a quantitative appraisal and analysis to be considered in helping to distinguish the likelihood of various disaster scenarios. However, the experience and experimental data of actual fires in buildings are not usually available. So a selected panel or a group of professionals is needed to participate in the making of judgment through the Delphi techniques. This has been done by a set of questionnaires for the building occupants and also another questionnaires that were specifically set for the discussion and judgment of the professionals. The results are very important as they provide a rational and flexible approach on how to select components of the available technology. Because of that, a method of measuring fire safety levels needs to be developed. Normally, a simple comparison with a norm is usually a "points scheme". A set of questionnaires has been used in the survey and discussions among the professionals to derive the point's scheme. Therefore, it was used to develop the framework of the fire safety evaluation procedure. The fire safety evaluation scheme that was developed for the patient areas within hospitals for the Department of Health and Social Services [1] formed the conceptual basis for the present development. The process of making the Evaluation Points Scheme for educational establishment was undertaken in the following steps:-

a) Establish the "NORM"

b) Establish the fire safety components.

c) Establish the policy, objectives and tactics to achieve.

d) Set up the questionnaire for the Delphi Group - fire safety professionals

e) Establish the contribution number or point's scheme for each of the fire safety components, tactics, objectives and policy based on their interrelationships.

f) Set up the Evaluation/Assessment Check List

g) Application of Check List.

\subsection{Points scheme}

Using point's scheme is basically to form the base for further judgement on the adequacy of fire safety components or the level of safety against the level of risk or hazard of fire that is available within the system in a particular area. The areas then can be summarised in terms of their acceptable or not acceptable level of fire safety based on the total number of points scored compared to the stated benchmark. The benchmark then leads the evaluator to make a decision on the adequacy of fire safety for that areas involved or even the whole building as a total evaluation. The Fire Safety Evaluation Using Points Scheme has a number of benefits, among them are:-

1. To be able to evaluate an area for it's fire safety adequacy with respect to the level of acceptability.

2. Areas of building being evaluated will lead to the evaluation of the whole building in terms of overall fire safety requirement or performance. 


\section{Environmental Health Risk}

3. Buildings within the systems or premises that has been evaluated for it's fire safety requirement will give an overall assessment of the whole school buildings against possible danger of fire in total.

4. Using the point's scheme can convince the non-technical professionals and authorities on the importance of considering fire safety. They are mainly involved with decision-making, and should know the seriousness of the need to comply with the fire safety requirements.

5. Comparison between schools within the educational establishment can help the Ministry of Education or any authority to make decisions on the current and future development of the establishment particularly in creating a safer environment with all the essential safety provisions. This involves the allocation of budget, facilities, building design, level of supervision and provision needed. Also involved the maintenance of the buildings and activities of the education curriculum. This would enable the available money to be spent to the best advantage.

6. The most important aspects of the study is that, the education administrators will be able to help in achieving the Fire Safety Policy for The Educational Establishment along with the National Educational Policy.

\subsection{The Framework Interaction Points Schemes - questionnaire}

There are 4 steps or level of sets of questionnaires, as shown in the following interaction, Diagram 1.0.

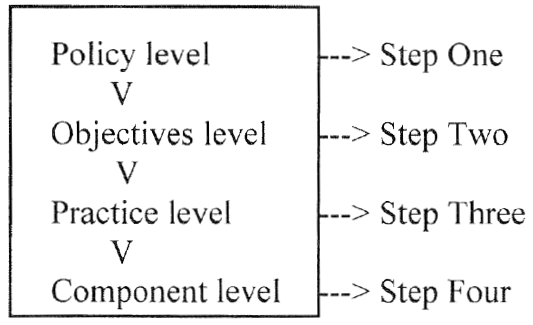

Diagram 1.0: Hierarchical Framework Interaction Stages

The questionnaires were designed into 3 parts:

a. The explanatory notes on the purpose and objectives of the questions in each division. This is to guide the experts or respondents of the questionnaire regarding the limitation that should not be exceeded.

b. The interaction boxes and arrows between the levels of the hierarchical framework.

c. The contribution number between 0 to 10 is to be given or written in each of the boxes provided. Each of the number is explained to what extent they are contributing and those contribution numbers represent a range of limitation. Only one number should be given for each interaction. 


\subsubsection{Objective vs policy (step 1)}

The result of objectives to policy vector obtained from the analysis of the questionnaires for the given values by the Delphi Group is shown in Table 1.0. The Objectives are mainly to achieve the Fire Safety Policy of the Residential Secondary School in Malaysia. The life safety still remains as the priority objectives in achieving the total fire safety policy for the educational establishment.

Table 1.0: Objectives To Policy Vector

\begin{tabular}{|l|c|c|}
\cline { 2 - 3 } \multicolumn{1}{c|}{} & \multicolumn{2}{c|}{ POLICY } \\
\hline OBJECTIVES & Average & $\begin{array}{c}\text { Percentage } \\
\mathbf{s}\end{array}$ \\
\hline Life Safety & 9.6 & $25 \%$ \\
\hline Property Protection & 7.0 & $18 \%$ \\
\hline Education Continuity & 6.9 & $18 \%$ \\
\hline Education Environment & 5.3 & $14 \%$ \\
\hline Public Anxiety & 5.0 & $13 \%$ \\
\hline Economy & 5.3 & $14 \%$ \\
\hline
\end{tabular}

\section{The matrix development}

The target in designing the checklist is to get the agreement on the contribution points for the interaction between the fire safety policy, objectives, tactics and components of the hierarchical framework. The fire safety inter-related contribution relationship given earlier is only between two hierarchies. The values given through the first interaction need to be manipulated to form other values which will bring a complete inter-related contribution values between each of the fourteen components to the overall fire safety policy. Matrix multiplication was used to achieve this purpose. Therefore, the Delphi Group has given values to the objectives-to-policy vector, a tactics-to-objectives matrix, a component-to-tactics matrix and a component-to-components matrix. Now, the same approach of using the multiplication of these matrixes as suggested in the Hospital Scheme [2] is applied, a vector for the contribution of tactics-to-policy and another vector of components to overall policy was produced. Suggestion by Saaty [3]:

3 method of column normalisation of a matrix:

i) Set the maximum component equal to 1 .

ii) The minimum component equal to 1 .

iii) Make the components of any column sum to unity. (most preferably) 


\section{Environmental Health Risk}

Table 2.0: Matrix Multiplication of Percentages Contribution Matrices

It is invariably desirable that the components of the final vector should sum to a fixed constant, e.g.: unity or $100 \%$.

Objectives

Tactic

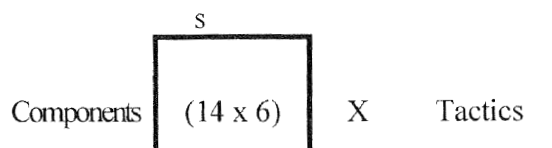

Policy

(A)

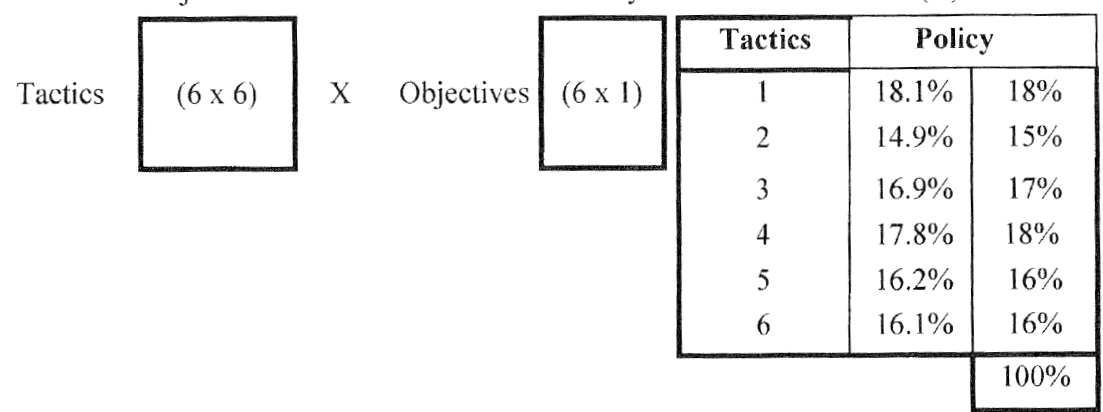

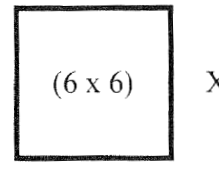

\begin{tabular}{|c|c|c|c|c|c|c|c|}
\hline \multirow{4}{*}{ Components } & \multirow{4}{*}{$\begin{array}{l}\text { Tactic } \\
\mathrm{s} \\
(14 \times 6)\end{array}$} & \multirow{4}{*}{$\mathrm{X}$} & \multirow{4}{*}{ Tactics } & \multirow{4}{*}{$\begin{array}{c}\text { Policy } \\
(6 \times 1) \\
(\mathrm{A})\end{array}$} & \multicolumn{3}{|c|}{$\mathrm{V} 2$} \\
\hline & & & & & \multirow{2}{*}{$\frac{\text { Components }}{\mathrm{A}}$} & \multicolumn{2}{|c|}{ Policy (V2\%) } \\
\hline & & & & & & $8.3 \%$ & $8 \%$ \\
\hline & & & & & B & $9.1 \%$ & $9 \%$ \\
\hline & & & & & C & $9.6 \%$ & $10 \%$ \\
\hline & & & & & D & $7.6 \%$ & $8 \%$ \\
\hline & & & & & $E$ & $6.3 \%$ & $6 \%$ \\
\hline & & & & & $\mathrm{F}$ & $8.2 \%$ & $8 \%$ \\
\hline & & & & & G & $8.1 \%$ & $8 \%$ \\
\hline & & & & & $\mathrm{H}$ & $5.3 \%$ & $5 \%$ \\
\hline & & & & & I & $6.9 \%$ & $7 \%$ \\
\hline & & & & & $\mathrm{J}$ & $5.9 \%$ & $6 \%$ \\
\hline & & & & & $\mathrm{K}$ & $6.9 \%$ & $7 \%$ \\
\hline & & & & & $\mathrm{L}$ & $6.6 \%$ & $7 \%$ \\
\hline & & & & & M & $7.5 \%$ & $7 \%$ \\
\hline & & & & & $\mathrm{N}$ & $3.6 \%$ & $4 \%$ \\
\hline & & & & & & & $100 \%$ \\
\hline
\end{tabular}




\begin{tabular}{|c|c|c|c|}
\hline & COMPONENTS & POINTS $\%$ & $\mathrm{~V} 2 \%$ \\
\hline A & $=$ BUILDING OCCUPANTS & 8.26 & 8 \\
\hline $\mathrm{B}$ & $=$ PREPARED FOR FIRE EMERGENCY & 9.12 & 9 \\
\hline $\mathrm{C}$ & $=$ FIRE PREVENTION & 9.63 & 9 \\
\hline $\mathrm{D}$ & $=$ INTERNAL ENVIRONMENT & 7.64 & 7.5 \\
\hline $\mathrm{E}$ & $=$ SERVICES & 6.33 & 6 \\
\hline $\mathrm{F}$ & $=$ DETECTION & 8.16 & 8 \\
\hline G & $=$ COMMUNICATION AND ALARM & 8.12 & 8 \\
\hline $\mathrm{H}$ & $=$ EGRESS OR ESCAPE & 5.33 & 5.5 \\
\hline I & $=$ FIRE FIGHTING & 6.87 & 7 \\
\hline $\mathrm{J}$ & $=$ PROTECTED AREAS & 5.92 & 6 \\
\hline $\mathrm{K}$ & $=$ AUTO SUPPRESSION & 6.89 & 7 \\
\hline $\mathrm{L}$ & $=$ SMOKE MOVEMENT CONTROL & 6.64 & 7 \\
\hline M & $=$ BUILDING STRUCTURE & 7.45 & 7.5 \\
\hline \multirow[t]{2}{*}{$\mathrm{N}$} & $=$ EXTERNAL ENVIRONMENT & 3.64 & 4.5 \\
\hline & & & $\underline{100}$ \\
\hline
\end{tabular}

\section{Acceptability and equivalency [4]}

The safety and risks factors available within the survey volume need to be balanced with the types of potential fire hazards that may occur. The acceptable level of safety is usually been defined through legislation and in order to evaluate the performance of safety components for an area will probably not require all the fourteen listed components. So, normally the evaluator is expected to evaluate only the safety component(s) that exist within the survey volume that perhaps help to reduce the risks to property, mission and people to a level which society regards as acceptable. In order to allow equivalency among the safety provision compared to the level of risks and hazards, a common sense is needed from the evaluator to assess the existing safety systems performance which are installed within the same building or nearby rooms to perform to the expected level of safety that may reduced the loss impact to an acceptable standard. It is important to ensure that the common safety system such as a hose reel system or fire extinguishers or P.A. systems installed within a single building could contribute the same level of safety performance expected for rooms on the same floor and these could help to reduce the total expenditure of the school budget by avoiding over spending or over design the safety systems required unless it is found to be inadequate. Another use of equivalency in terms of fire safety evaluation is when the evaluators or professionals are suggesting for the solutions of the safety requirements where the survey volume seems to be lacking off and categorised as being non-acceptable standard. The process may be called as Trade-off. 


\section{Environmental Health Risk}

\subsection{Example of the Checklists}

Therefore a step forward of the improved version of the evaluation checklist using points scheme on the performances of the fire safety components is shown in the next paragraph. It is called the Fire Safety Evaluation of Building Performance Checklist. The assessment of the sport hall is using percentages(\%) and survey grade $[0,5]$ as the comparison study.

Building Type:

Building Area:

Contribution

Values

Components

A. Building Occupants

B. Preparedness For Fire Emergency

C. Fire Prevention

D. Internal Environment

E. Services

F. Detection System

G. Communication and Alarm

H. Egress or Escape

I. Fire Fighting

J. Protected Areas

K. Auto Suppression

L. Smoke Movement/Control

M. Building Structure

N. External Environment

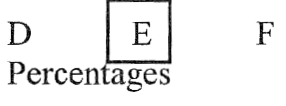

$\begin{array}{ll}90 \% & 8=720 \\ 70 \% & 9=630 \\ 80 \% & 9=720 \\ 80 \% & 7.5=600 \\ 80 \% & 6=480 \\ 60 \% & 8=480 \\ 50 \% & 8=400 \\ 95 \% & 5.5=522.5 \\ 50 \% & 7=350 \\ 85 \% & 6=510 \\ 0 & 7=0 \\ 75 \% & 7=525 \\ 80 \% & 7.5=600 \\ 70 \% & 4.5=315 \\ \text { Total } & =7572.5\end{array}$

$$
\mathrm{P}^{\prime}=\quad \sum_{\mathrm{n}}^{1->14}\left(\frac{\mathrm{Pp} \times \mathrm{Nc}}{10000}\right) 100 \%
$$

Overall Safety Performance $\mathrm{P}^{\prime}=75.73 \%$ (Acceptable level of safety and the standard is good). This evaluation observation checklist is considered to be the simplest way to assessed the performance of safety components within an area with adequate experience and having strong knowledge background in fire safety. However, using the survey grade score between 0 to 5 has given slightly different results compared to the perception percentages contribution calculation using the multiplication of the point's scheme. The results seem to fall within the same range of acceptable safety standard and the difference is only in terms of the way the evaluation processes were undertaken, either to use the survey grade $[0,5]$ or the more fine contribution using the perception percentages. It was stated in the hospital scheme (6) that it is important to bear In mind the coarseness of the grading system within which the survey will have been 
conducted where the 0 to 5 grading giving an accuracy of \pm 0.5 on each component.

\subsection{Scoring grade and percentages on perceptions}

Most of the building areas being considered in the survey checklist are enclosed areas with proper walls, ceilings and floors. Only need to evaluate one survey volume at a time by ticking the box corresponding to it. The evaluation can be done in two ways, first with perception percentages and second by survey grading 0 to 5 . Both of the scoring from perception percentages and survey grades can each be multiplied with the "N" contribution values which derived from the Delphi group using matrix multiplication method. "N" contribution values are actually the norm contribution values representing each of the components. The whole process in doing the evaluation using the checklist should able to be done quickly and simply. Assuming that all the components of fire safety are giving $100 \%$ safety and everything is taken into consideration then the assessing work for the area should based on the loss impact, vulnerability or threat.

Refer to table 3.0, therefore the best performance of an area against fire must be of low risk, less threat, less vulnerable to fire exposures and probably high safety measures. However, the worst performance of an area must be of high risk, highly vulnerable towards fire threat and low safety measures.

\subsection{Performances assessment}

Table 3.0: Reference for the performance scoring and percentages on perception

Zero, $0=$ The component is not available.

Survey Grade:

\begin{tabular}{|c|c|c|c|c|}
\hline 1 & 2 & 3 & 4 & 5 \\
\hline Worst & Bad & Average & Good & Very Good \\
\hline
\end{tabular}

Percentages perceptions:

\begin{tabular}{|c|c|c|c|c|}
\hline below $30 \%$ & $\begin{array}{c}30 \% \text { to } \\
40 \%\end{array}$ & $41 \%$ to $60 \%$ & $61 \%$ to $80 \%$ & $81 \%$ to $100 \%$ \\
\hline High Threat & & Average Threat & & Less Threat \\
\hline High Risk & & Medium Risk & & Low Risk \\
\hline Low Safety & & Medium Safety & & High Safety \\
\hline $\begin{array}{c}\text { Highly } \\
\text { Vulnerable }\end{array}$ & & (Vulnerability) & & Less \\
\hline
\end{tabular}




\section{Environmental Health Risk}

\section{Conclusion}

The production of the Building Performance Evaluation Points Scheme Checklist for the Educational Establishment has been undertaken with reference to the Hospital scheme. Consideration has been given to four major parts in order to produce the point's scheme or numerical assessment checklist. One is the selection of the panel members of the Delphi Group. Two, is the information needed for the design requirement of the checklist which involved the interaction of the inter-relation between the policy, objectives, tactics and components, the questionnaire design and method to conduct the meetings using Delphi approach. Three, is the formation of the points scheme by matrix multiplication for their interaction relationships and the design of the evaluation checklist. Four is the method of using the evaluation point's scheme checklist to evaluate the building areas in a typical school in Malaysia.

In general, the evaluation point scheme checklist is easy to use by the experts or by the trained personnel that will be doing the evaluation assessment. There are two ways of giving the evaluation scores either using own percentages perception or survey grade. The percentages perceptions requires more experiences and knowledge about the systems installed and having a very critical number of questions with good observation which is normally done by experts who give a slightly more detail scoring values. Whereas the survey grade values is a little bit rigid in terms of scoring and being used just to get the overall round number of safety contributions that is available within the survey volume. Taking photographs along with the walk through evaluation assessment could probably assist an observation. Therefore, the overall evaluation of fire safety acceptability standard for a school is obtained. The evaluation processes is very important to carry out at earlier stage so that precautions steps are established to cater for any unexpected fire occurrence. As a result, a fire safety cost benefit can be implemented together with the flexibility in design in order to overcome the problems created from danger of fire. Also the fire safety of the building is kept to the acceptable standard.

\section{References:}

[1] Marchant, E.W. et al., "Fire Safety Evaluation(Points) Scheme for Patient Areas within Hospitals", A report on its origins and development sponsored by the DHSS Department of Fire Safety Engineering, University of Edinburgh, 1982.

[2] Paul Stollard, "The Development of a Points Scheme to Assess Fire Safety in Hospitals", Department of Fire Safety Engineering, University of Edinburgh, The King's Buildings, Edinburgh, EH9 3JL, UK., Fire Safety Journal, 7, 1984, pp. 145-153.

[3] Saaty, Thomas L., "The Analytic Hierarchy Process", McGraw-Hill, New York, 1980.

[4] Rasbash, D. J., "Analytical Approach To Fire Safety", Fire Surveyor, Vol.9, No.4, August 1980, pp. 20-33. 